\title{
Modeling Low Intensity Fires: Lessons Learned from 2012 RxCADRE
}

\author{
Rodman R. Linn ${ }^{1, *}$, Judith L. Winterkamp ${ }^{1}$, James H. Furman ${ }^{2}$, Brett Williams ${ }^{3}$, J. Kevin Hiers ${ }^{4}$, \\ Alexandra Jonko ${ }^{1}$, Joseph J. O'Brien ${ }^{5}$, Kara M. Yedinak ${ }^{6}$ and Scott Goodrick ${ }^{5}$
}

Citation: Linn, R.R.; Winterkamp, J.L.; Furman, J.H.; Williams, B.; Hiers, J.K.; Jonko, A.; O’Brien, J.J.; Yedinak, K.M.; Goodrick, S. Modeling Low Intensity Fires: Lessons Learned from 2012 RxCADRE. Atmosphere 2021, 12, 139. https://doi.org/10.3390/ atmos12020139

Academic Editors: Khalid Moinuddin and Jason J. Sharples

Received: 22 December 2020

Accepted: 12 January 2021

Published: 22 January 2021

Publisher's Note: MDPI stays neutral with regard to jurisdictional claims in published maps and institutional affiliations.

Copyright: (c) 2021 by the authors. Licensee MDPI, Basel, Switzerland. This article is an open access article distributed under the terms and conditions of the Creative Commons Attribution (CC BY) license (https:/ / creativecommons.org/licenses/by/ $4.0 /)$.
1 Los Alamos National Laboratory, Earth and Environmental Science Division, Los Alamos, NM 87545, USA; judyw@lanl.gov (J.L.W.); ajonko@lanl.gov (A.J.)

2 United States Department of Agriculture Forest Service, Eastern Region, Milwaukee, WI 53202, USA; james.h.furman@usda.gov

3 United States Air Force Civil Engineer Center, Air Force Wildland Fire Branch, Niceville, FL 32578, USA; brett.williams.4@us.af.mil

4 Tall Timbers Research Station, Tallahassee, FL 32312, USA; jkhiers@talltimbers.org

5 United States Department of Agriculture Forest Service, Southern Research Station, Athens, GA 30602, USA; jjobrien@fs.fed.us (J.J.O.); scott.l.goodrick@usda.gov (S.G.)

6 United States Department of Agriculture Forest Service, Forest Products Laboratory, Madison, WI 53726, USA; kara.yedinak@usda.gov

* Correspondence: rrl@lanl.gov

\begin{abstract}
Coupled fire-atmosphere models are increasingly being used to study low-intensity fires, such as those that are used in prescribed fire applications. Thus, the need arises to evaluate these models for their ability to accurately represent fire spread in marginal burning conditions. In this study, wind and fuel data collected during the Prescribed Fire Combustion and Atmospheric Dynamics Research Experiments (RxCADRE) fire campaign were used to generate initial and boundary conditions for coupled fire-atmosphere simulations. We present a novel method to obtain fuels representation at the model grid scale using a combination of imagery, machine learning, and field sampling. Several methods to generate wind input conditions for the model from eight different anemometer measurements are explored. We find a strong sensitivity of fire outcomes to wind inputs. This result highlights the critical need to include variable wind fields as inputs in modeling marginal fire conditions. This work highlights the complexities of comparing physics-based model results against observations, which are more acute in marginal burning conditions, where stronger sensitivities to local variability in wind and fuels drive fire outcomes.
\end{abstract}

Keywords: fire modeling; low intensity fire; prescribed fire; model-observation comparison

\section{Introduction}

Interest has been growing in the application of coupled fire-atmosphere modeling to study prescribed fires burning in marginal burn conditions [1,2]. Here, marginal conditions refer to those under which fire spread depends on the localized (in time or space) heterogeneities in fuels and wind fields. Under these conditions, fire intensity is low, fireline depths are narrow, firelines are often broken and the fire's ability to spread is variable. To date, coupled fire-atmosphere models have predominantly been applied to study highintensity wildfires. However, it is important to assess coupled fire-atmopshere models' applicability to low-intensity fires, which are more sensitive to small environmental variations [3]. Here, we use observations of fuels and atmospheric conditions collected during the 2012 Prescribed Fire Combustion and Atmospheric Dynamics Research Experiments (RxCADRE) campaign [4] to drive simulations of low-intensity fires in marginal conditions and evaluate modeled fire behavior using observations.

Physics-based coupled fire-atmosphere models fall on the far end of the spectrum of wildland fire models, ranging from purely empirical to theoretical physics-based, with 
various combinations in between $[5,6]$. While empirical models, such as the Rothermel fire spread based model BEHAVE $[7,8]$, represent empirically based functional relationships between aspects of fire behavior, such as rate of spread (ROS) or fire intensity, and the ambient conditions under which the fire is burning, three-dimensional fuel properties and atmospheric conditions must be explicitly specified at the resolution of the computational grid in order to initialize coupled fire-atmosphere models. The more complete the explicit specification of fuels and winds, the fewer unstated assumptions are made. In reality, each simulation is a complex trade-off involving the availability of detailed data, the process simplifications in the model, and assumptions concerning the mean and spatiotemporal variability of fuels and winds not sampled. The sensitivity of physics-based models to the details of input conditions can vary significantly between higher intensity and lower intensity fires. Characterizing this sensitivity remains an area of ongoing research.

Fire model applications have historically focused on fires that pose a significant risk to lives or infrastructure. However, more recent applications include modeling of fire behavior in the context of prescribed fires [1,2]. Prescribed fires target a narrow window of fire intensities, bounded by conditions where (1) fire can be sustained and will carry through the fuels [9], and (2) fire intensity is not sufficient to escape the confines of the managed area or cause unwanted ecological damage $[10,11]$. The behavior of low intensity fires is sensitive to different aspects of the fire environment relative to high intensity fires. Thus, a model capable of simulating the spread of a crown fire may not be able to represent the behavior of a low intensity surface fire burning under marginal conditions [12]. As the intensity of the fire declines, the importance of finer-scale heterogeneity in the fuels and wind patterns increases, adding challenges to fire modeling as fire-length scales decrease with respect to computational grid resolution. As fire models are increasingly used to assist decision making in prescribed fire scenarios, it is important to evaluate their performance and level of uncertainty under marginal burning conditions, including slower wind speeds, lighter fuel loads, and higher moisture levels than those associated with wildfires. Comparison with observations is critical to this evaluation.

Previous comparisons of physics-based models to wildfire observations and field experiments can be divided into two categories: (1) comparisons of trends, averaged over many simulations and observations, and (2) comparisons of model results to observations of individual fires. Comparisons of trends [13], with parallels to the development of empirical models, can match macro-scale responses to environmental conditions, such as wind speed, but cannot assess a physics-based model's ability to accurately represent the physical drivers of specific observed behaviors. Comparisons with individual wildfire observations and experiments are more common model applications [14-22]. Results from these experiments are complicated to interpret because conditions for observed wildfires are usually not sufficiently characterized to connect specifics of spatially heterogeneous and dynamic winds and heterogeneous fuels with specific burn characteristics of a fire at a given moment in time. This data mismatch forces assumptions, homogenization, or estimates to fill gaps in model inputs. These assumptions and estimates translate to uncertainty in model results. This is also the reason why most empirical models are developed based on statistical analysis of numerous observations.

To date, no such comparisons have been performed under marginal burning conditions, in part because no well-characterized data sets were available until the Prescribed Fire Combustion and Atmospheric Dynamics Research Experiments (RxCADRE) [4]. The 2012 RxCADRE campaign included a number of prescribed burns at different scales, ranging from 2 ha to 454 ha. These experimental burns were intended to provide a comprehensive, multi-scale dataset for evaluating coupled fire-atmosphere combustion and smoke models, which have historically lacked experimental data to support or refute the complex fire-atmospheric interactions that they attempt to capture [23]. Data collected in 2012 leveraged relatively homogeneous fuel beds, flat terrain, and common ignition patterns to capture the range of variation in fire behavior resulting from subtle fuel, local weather, and fire line interactions. To date, these data have largely been used to evaluate smoke 
model errors [24,25], quantify model uncertainties associated with smoke transport, assess heat-release patterns [26,27], and examine near-fire micrometeorology [28]. Fire behavior models have been challenged by heterogeneity within the light fuel loads and relatively low turbulent wind fields present during the RxCADRE burns [28], which are characteristic of environmental conditions for many prescribed burns.

Leveraging the fuel and wind measurements collected as part of the 2012 RxCADRE campaign, we have explored physics-based simulations of low-intensity fire in marginal conditions with FIRETEC [29-31], a coupled fire-atmosphere model, and compared results to observed fire behavior [31-33]. FIRETEC is one of three models in its class. The other physics-based coupled fire-atmosphere models capable of representing the interacting heat transfer, fluid dynamics, and combustion that determine fire behavior are the Wildland Fire Dynamics Simulator (WFDS) [16,34] and FIRESTAR 3D [35]. FIRETEC was used to model a $200 \mathrm{~m} \times 100 \mathrm{~m}$ (2 ha) plot, S5 [4], which represents the most "straight-forward" and data rich of the RxCADRE 2012 fires. We present lessons learned regarding data requirements for initializing and bounding simulations of marginal-burning fires.

\section{Experimental Data}

The comparisons carried out in this study leveraged empirical data from the S5 burn experiment of the 2012 RxCADRE field campaign conducted at Eglin Air Force Base [4]. FIRETEC inputs included fuel configuration and atmospheric condition before ignition, as well as upwind atmospheric conditions for the duration of the fire. The input data were derived from published and archived sources from RxCADRE [4,28,36-39].

\subsection{Fuels}

The RxCADRE S5 plot (Figure 1) was planned by RxCADRE principal investigators as a homogenous mixture of fuels from a macro perspective, at 100-m to $\mathrm{km}$ scales. However, similar to other southeastern fuels [40], fuels in S5 were quite heterogeneous at scales from 1-10 $\mathrm{m}^{2}$, as seen in Figures 1 and 2. Fuel heterogeneity at meter scales can be resolved explicitly by FIRETEC, which has a horizontal spatial resolution of 1-2 m. Thus, variation in fuel types has the potential to significantly impact fire behavior (e.g., woody goldenrod (Chrysoma pauciflosculosa (Michx.) Greene) typically has high live fuel moisture content and rarely burns, while tall bunchgrass is flashy). To represent the meter-scale variability of fuels in the S5 plot, we used a combination of high-resolution $(0.15 \mathrm{~m})$ images of the area taken before the burn, in 2010 (courtesy of Eglin Air Force Base Geointegration Office), and data collected during a site visit after the burn in November 2013.

We identified meter-scale regions of relatively heterogeneous fuel within the S5 plot during the site visit. These regions were recorded with GPS coordinates and imagery, which also documented their spatial relationship to other fuel types, such as perennial shrubs. Seven major fuel types for the S5 plot were identified: short grass (characteristic height: $0.2 \mathrm{~m}$, characteristic fuel load: $\left.0.29 \mathrm{~kg} \mathrm{~m}^{-2}\right)$, tall grass $\left(0.8 \mathrm{~m}, 0.55 \mathrm{~kg} \mathrm{~m}^{-2}\right)$, saw palmetto (Serenoa repens (Bartram) J.K. Small) $\left(0.4 \mathrm{~m}, 0.22 \mathrm{~kg} \mathrm{~m}^{-2}\right)$, little bluestem (Schizachyrium rhizomatum (Swallen) Gould) $\left(0.3 \mathrm{~m}, 0.07 \mathrm{~kg} \mathrm{~m}^{-2}\right)$, woody goldenrod $(0.2 \mathrm{~m}$, $0.19 \mathrm{~kg} \mathrm{~m}^{-2}$ ), clay road, and bare ground or sand. While the road is technically bare ground, road and bare ground were classified separately because the improved clay road surface gives it a different appearance, which was used for visual reference. The different surface types can be seen in visible spectrum imagery provided by Eglin Air Force Base as different colors. Agreement in vegetation patterns in the 2010 imagery and in data collected in 2013 suggests that this data is representative of fuels present at the time of the burn. 

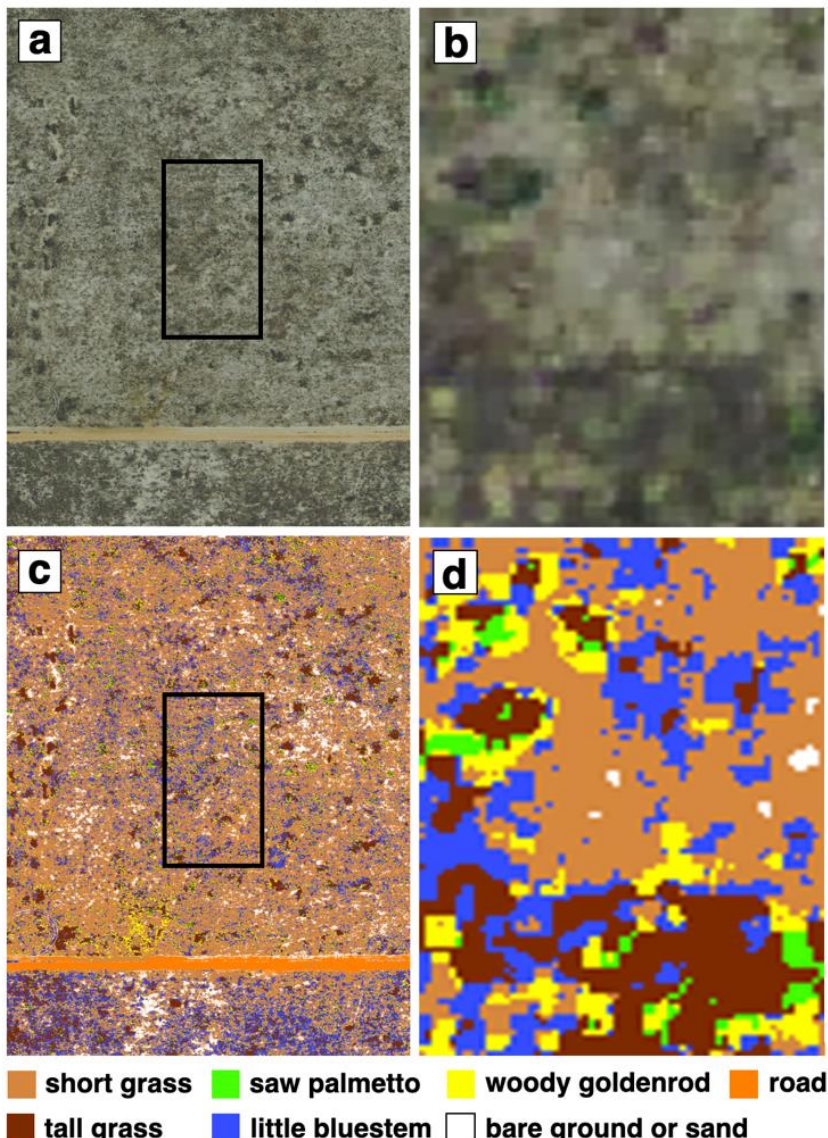

Figure 1. Fuel class verification. (a) High-resolution $(0.15 \mathrm{~m})$ raw visible spectrum imagery of the landscape within the FIRETEC computational domain surrounding S5 (400 m by $600 \mathrm{~m}$ ), with S5 boundary shown in black. (b) Visible image zoomed $(10 \mathrm{~m} \times 15 \mathrm{~m})$ to show detail near the center of S5. (c,d) GENIE fuels classifications for the domains shown in $(\mathbf{a}, \mathbf{b})$, respectively. Image courtesy of Eglin Air Force Base Geointegration Office.
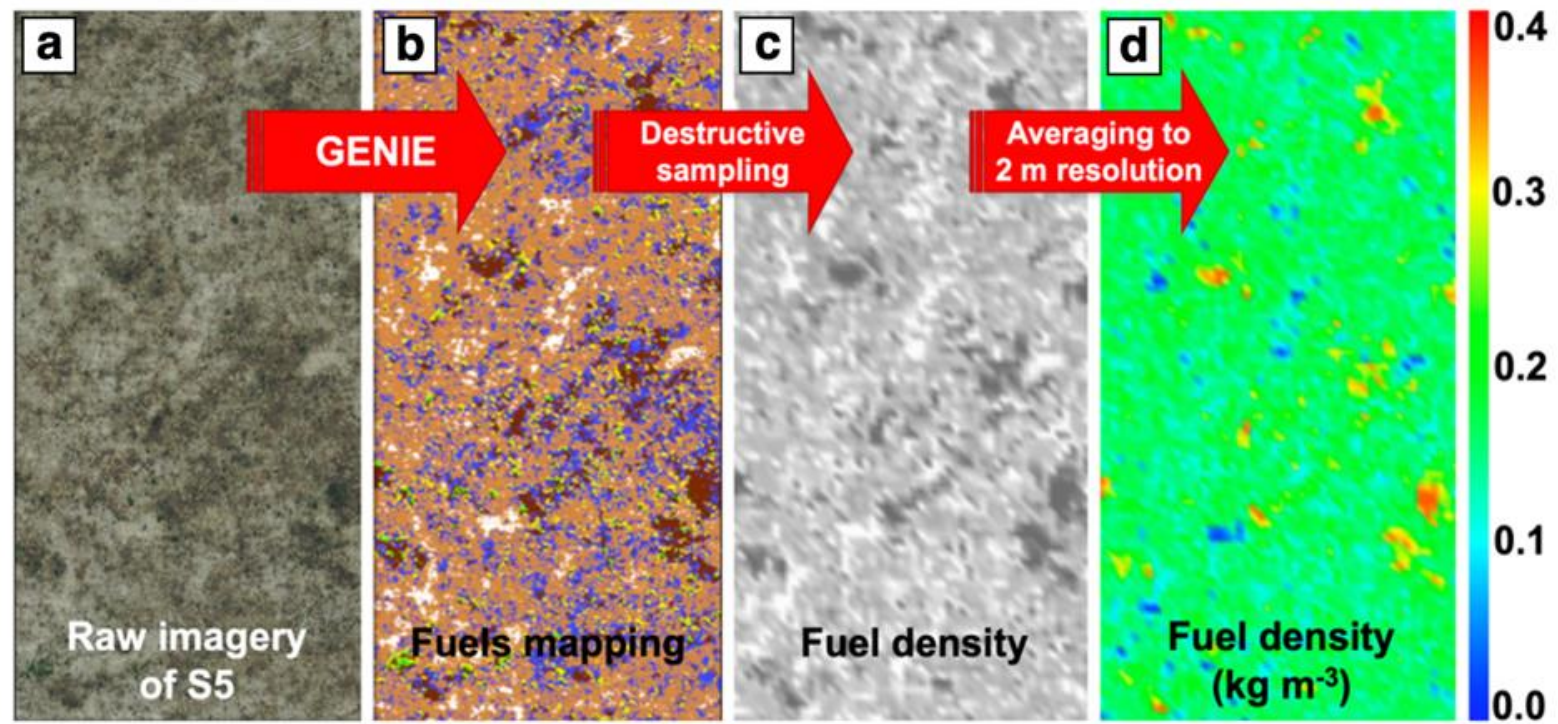

0.3

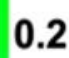

0.1

Figure 2. Flow chart for processing of (a) raw $0.15 \mathrm{~m}$ imagery through (b) fuels classification mapping using the Genie software at $0.15 \mathrm{~m}$ resolution, (c) associating fuel properties from destructive sampling with each pixel from the Genie-based classification and (d) building fuel data such as fuel density at $2 \mathrm{~m} \times 2 \mathrm{~m}$ resolution for use in FIRETEC. 
We identified examples of each of the seven dominant fuel types in the image and used them to train a commercially available adaptive feature extraction software package, Genie Pro 2.4 (Copyright 2007-2012 Observera, Inc., Chantilly, VA, USA). Genie classified the remaining portions of the image (approximately 98\%), as seen in Figure 1c,d. This classification was accomplished using an iterative process. We used known fuel types to guide an initial Genie-based classification, and then compared regions classified by Genie to known fuel types for validation. In locations where the classification was incorrect, we trained Genie again using additional known fuels, and reclassified the entire image. This process was repeated until close visual inspection of the classification showed no notable differences. Eglin Air Force Base fire managers then verified that the classification captured the major features of fuel patterns by comparing specific fuel types and transitions in the image-based classification and in the field.

Next, fuel properties, including fuel load, height, surface-area-per-volume, and moisture, were associated with each fuel type and assigned to each $15 \mathrm{~cm}$ pixel of the highsolution image. Fuel load, height and surface-area-per-unit-volume were obtained from destructive sampling completed just prior to the burn in 2012 [4]. Fuel moisture values representative of dry fuels were assigned to each pixel. While live fuels were also present, in this fuel complex dead fuels carry the fire, while live fuels do not contribute significantly to fire spread. The implications of our approach, which essentially neglects live fuel moisture, will be investigated in subsequent research.

Finally, the $15 \mathrm{~cm}$ pixels were averaged to 2-m FIRETEC grid resolution, as illustrated in Figure 2 for fuel density. While this methodology worked well for this particular burn site, where the vegetation is low in height with a limited number of dominant species that grow in meter-scale patches, it would present more challenges in areas where fuels are more complex or have multiple vertical layers. At the time of this work, techniques for converting terrestrial LIDAR data into high-resolution fuel input conditions were not sufficiently mature to be used. Terrestrial LIDAR techniques [41] are expected to simplify the fuel bed development process in the future.

\subsection{Winds}

As part of the RxCADRE experiment, 27 tower-based anemometers were distributed around the S5 plot (Figure 3; [28]). Twenty-four anemometers surrounded the S5 plot, spaced approximately $30 \mathrm{~m}$ from each other and $40 \mathrm{~m}$ from the northwest (upwind) S5 boundary, $30 \mathrm{~m}$ from the southeast (downwind) S5 boundary, and $20 \mathrm{~m}$ from the other boundaries. Three additional anemometers were arranged in a line stretching to the northeast of the plot, based on forecasts of the prevailing wind direction during the burn. On the day of the burn, however, the wind direction was from the north, rather than northwest.

The anemometers recorded instantaneous wind speed, $S$, and direction, $\alpha$, in intervals of $3 \mathrm{~s}$. Wind direction $\alpha$ is defined as the direction from which the wind blows in degrees clockwise from north. Ten of the 27 anemometers were considered upwind of the plot based on the nominally north ambient wind on the day of the burn. These anemometers are marked with blue or red circles in Figure 3 and their wind measurements are shown in Figures 4 and 5. Of these ten upwind anemometers, two (A47 and A77, shown as red circles in Figure 3) were in disagreement with the other sensors in terms of their wind direction (black lines in Figure 4b). For the purpose of this study, we assumed that these statistical outliers have sensor misalignment errors and excluded them. While wind measurements at the remaining eight upwind anemometers (colored lines in Figure 4) exhibited some variability as well, it is impossible to distinguish between wind field heterogeneity and measurement error. For the purpose of this study, we have assumed that differences between the sensors at any given point in time reflect spatial and temporal variability in the wind field. 


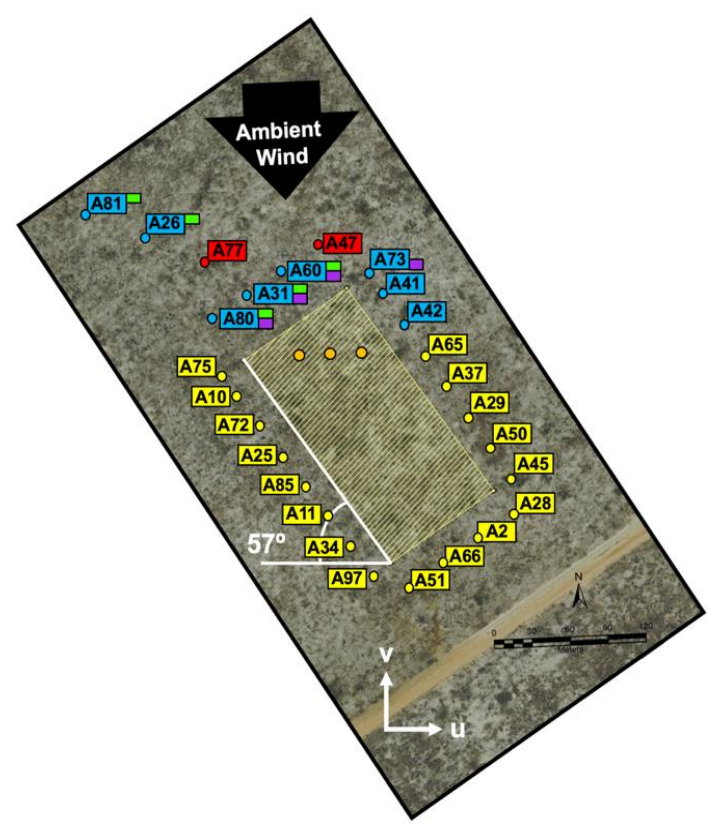

Figure 3. Layout of the S5 plot (hashed area) relative to the ambient wind. The plot was instrumented with 27 anemometers shown as yellow, blue or red numbered circles. Blue and red circles indicate anemometers considered upwind relative to the ambient wind on the day of the burn. Green flags mark anemometers included in the 5-sensor average, while purple flags mark anemometers included in 4-sensor average. Orange circles mark the center and ends of the ignition line.

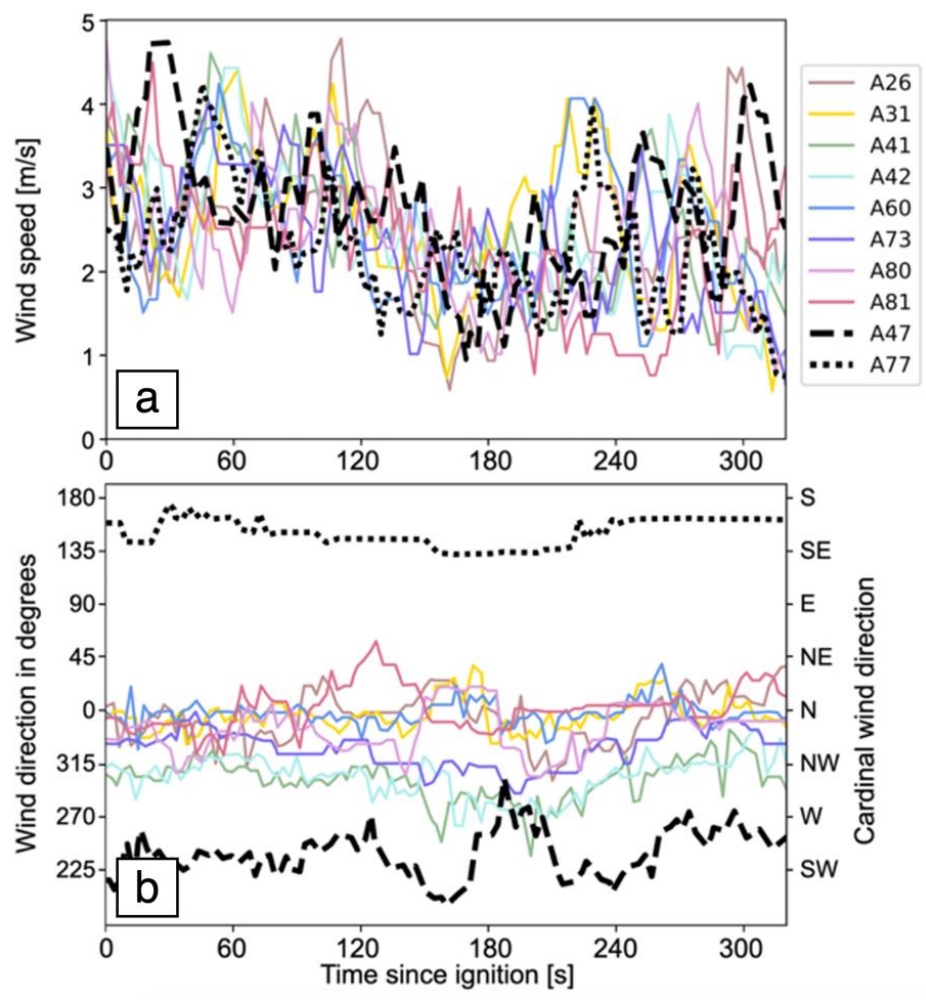

Figure 4. Wind speed (a) and direction (b) measured in $3 \mathrm{~s}$ intervals for the 10 upwind anemometers. A47 and A77 (black, bold lines) were excluded from the analysis because their measurements of wind direction differ substantially from the remaining sensors. These anemometers are marked with red circles in Figure 3. 

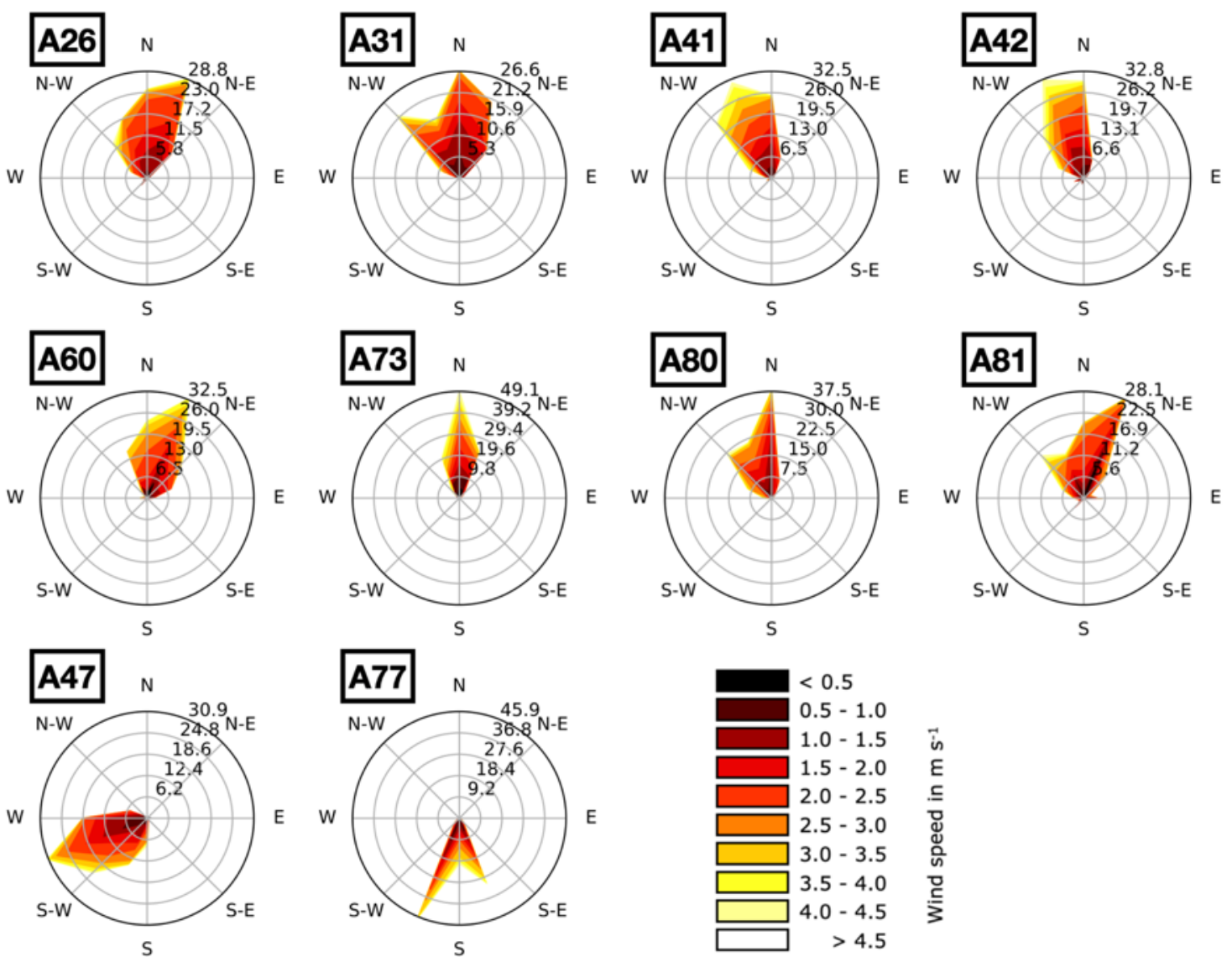

Figure 5. Windroses show the wind speed and direction measured at the 10 anemometers considered upwind of the burn plot. Circular levels indicate percentage of time a wind direction was observed, and colors indicate associated wind speeds. Anemometers A47 and A77 at the bottom were excluded from this study due to large differences in wind direction relative to the other sensors.

For each sensor $n$ and each point in time after ignition, we calculated orthogonal wind velocity components, $u_{n}$ and $v_{n}$, using Equation (1):

$$
\begin{gathered}
u_{n}=-S_{n} \sin \left(\alpha_{n}\right) \\
v_{n}=-S_{n} \cos \left(\alpha_{n}\right)
\end{gathered}
$$

$u_{n}$ is the west to east component and $v_{n}$ is the south to north component. We obtained the time-averaged wind magnitude $\overline{S_{n}}$ and direction $\overline{\alpha_{n}}$ for each anemometer from time averages of $u$ and $v$ components, $\overline{u_{n}}$ and $\overline{v_{n}}$, based on Equation (2):

$$
\begin{gathered}
\overline{\mathrm{S}}_{\mathrm{n}}=\sqrt{\overline{\overline{\mathrm{u}}}_{\mathrm{n}}^{2}+\overline{\mathrm{v}}_{\mathrm{n}}{ }^{2}} \\
\bar{\alpha}_{\mathrm{n}}=\operatorname{atan}\left(\frac{\overline{\mathrm{u}}_{\mathrm{n}}}{\overline{\mathrm{v}}_{\mathrm{n}}}\right)
\end{gathered}
$$

The time-averaged magnitude obtained through this calculation is the magnitude of the mean velocity vector over $320 \mathrm{~s}$. This differs from averaging the instantaneous wind speeds measured by the anemometers because the average of the anemometer wind speeds does not account for wind direction. Consider four anemometer measurements: $1 \mathrm{~m} \mathrm{~s}^{-1}$ from the north, $1 \mathrm{~m} \mathrm{~s}^{-1}$ from the east, $1 \mathrm{~m} \mathrm{~s}^{-1}$ from the south and $1 \mathrm{~m} \mathrm{~s}^{-1}$ from the west. The simple average of these wind speeds would be $1 \mathrm{~m} \mathrm{~s}^{-1}$, but the magnitude of the time-averaged mean velocity vector would be $0 \mathrm{~m} \mathrm{~s}^{-1}$.

Due to our definition of the mean speed and mean angle, the time average of the component of the instantaneous wind in the direction of the mean wind is $\overline{u_{\| \bar{\alpha}_{n}}}=\bar{S}_{n}$ and time average of the component of the wind perpendicular to the mean wind direction 
is $\overline{u_{\perp \bar{\alpha}_{n}}}=0$. Perturbations from the temporal mean are computed as follows: $u^{\prime} \| \bar{\alpha}_{n}=$ $-u_{n}^{\prime} \sin \left(\bar{\alpha}_{n}\right)-v_{n}^{\prime} \cos \left(\bar{\alpha}_{n}\right)$ and $u^{\prime}{ }_{\perp \bar{\alpha}_{n}}=-u_{n}^{\prime} \cos \left(\bar{\alpha}_{n}\right)+v^{\prime}{ }_{n} \sin \left(\bar{\alpha}_{n}\right)$.

The perturbations were used to compute standard deviations of wind parallel to the mean wind direction, $\sigma(u \| \bar{\alpha})$, and of wind perpendicular to mean wind direction, $\sigma(u \perp \bar{\alpha})$. We computed the mean kinetic energy of the horizontal flow per unit mass (MKE) and turbulence kinetic energy (TKE) as:

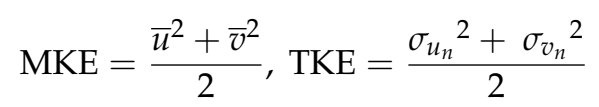

where $\sigma$ is the standard deviation. The total average kinetic energy is the sum of the TKE and MKE. While turbulent fluctuations in the vertical direction were also present, they were not recorded by the anemometers and vertical velocities were disregarded in our analysis. Anemometers were positioned tens of meter from the fire, and close enough to the ground to limit the length scales associated with vertical fluctuations at the anemometer locations. It is likely that the vertical fluctuations felt at the anemometers were not correlated to those at the fire. Statistics computed using Equation (1) through (3) above for the eight upwind anemometers are shown in Table 1.

Table 1. Statistics computed using wind data from the eight anemometers used in the study.

\begin{tabular}{|c|c|c|c|c|c|c|c|c|}
\hline Sensor & $\begin{array}{l}\bar{S}\left(\mathrm{~ms}^{-1}\right) \\
\quad \pm \sigma_{\bar{S}}\end{array}$ & $\bar{\alpha} \pm \sigma_{\bar{\alpha}}$ & $\begin{array}{c}\sigma(u|| \bar{\alpha}) \\
\left(\mathrm{ms}^{-1}\right)\end{array}$ & $\begin{array}{r}\sigma(u \perp \bar{\alpha}) \\
\left(\mathrm{ms}^{-1}\right)\end{array}$ & $\begin{array}{c}\bar{u}\left(\mathrm{~ms}^{-1}\right) \\
\quad \pm \sigma_{\bar{u}}\end{array}$ & $\bar{v}\left(\mathrm{~ms}^{-1}\right) \pm \sigma_{\bar{v}}$ & $\begin{array}{c}\text { MKE } \\
\left(\mathrm{m}^{2} / \mathrm{s}^{2}\right)\end{array}$ & $\begin{array}{c}\text { TKE } \\
\left(\mathrm{m}^{2} / \mathrm{s}^{2}\right)\end{array}$ \\
\hline A81 & $2.17 \pm 0.81$ & $3.91 \pm 18.10$ & 0.76 & 0.80 & $-0.15 \pm 0.79$ & $-2.17 \pm 0.77$ & 2.35 & 0.60 \\
\hline A26 & $2.35 \pm 0.91$ & $-3.95 \pm 21.72$ & 0.92 & 0.86 & $0.16 \pm 0.85$ & $-2.35 \pm 0.92$ & 2.77 & 0.79 \\
\hline A 80 & $2.28 \pm 0.84$ & $-15.55 \pm 20.05$ & 0.86 & 0.73 & $0.61 \pm 0.76$ & $-2.19 \pm 0.83$ & 2.58 & 0.64 \\
\hline A31 & $2.49 \pm 0.87$ & $-5.79 \pm 14.06$ & 0.90 & 0.48 & $0.25 \pm 0.52$ & $-2.48 \pm 0.87$ & 3.11 & 0.52 \\
\hline A60 & $2.47 \pm 0.85$ & $-1.26 \pm 10.52$ & 0.86 & 0.38 & $0.05 \pm 0.39$ & $-2.47 \pm 0.86$ & 3.05 & 0.44 \\
\hline A73 & $2.29 \pm 0.78$ & $-29.66 \pm 16.16$ & 0.78 & 0.62 & $1.13 \pm 0.56$ & $-1.99 \pm 0.83$ & 2.62 & 0.50 \\
\hline A41 & $2.43 \pm 0.81$ & $-56.24 \pm 18.23$ & 0.85 & 0.62 & $2.02 \pm 0.64$ & $-1.35 \pm 0.84$ & 2.95 & 0.56 \\
\hline A42 & $2.44 \pm 0.78$ & $-54.66 \pm 17.49$ & 0.79 & 0.69 & $1.99 \pm 0.60$ & $-1.41 \pm 0.86$ & 2.97 & 0.55 \\
\hline
\end{tabular}

The highest mean wind speed was recorded at A31, at $2.49 \mathrm{~m} \mathrm{~s}^{-1}$, and the lowest mean wind speed was recorded at A81 at $2.17 \mathrm{~m} \mathrm{~s}^{-1}$ ( $15 \%$ variation between sensors). The minimum and maximum values of mean kinetic energy were found at the same sensors. TKE, which quantifies turbulent deviations from the mean wind, peaked at A26, and was lowest at A60. A31 and A60 were located directly upwind of the burn plot, while A81 and A26 were farthest away from the burn plot. Thus, at the time of data collection, areas of relatively strong mean winds were co-located with low TKE, and vice versa. We hypothesize that the lower TKE values at locations closer to the fire were due to the fact that the sustained indraft from the fire damped the fluctuations in the background wind field. This analysis did not provide sufficient data to evaluate this hypothesis, but it will be addressed in future research.

\subsubsection{Temporal Wind Variability}

The standard deviation of wind speeds (Table 1, C2) ranged from $0.78 \mathrm{~m} \mathrm{~s}^{-1}$ to $0.91 \mathrm{~m} \mathrm{~s}^{-1}$ with a mean of $0.83 \mathrm{~m} \mathrm{~s}^{-1}$, indicating temporal wind variation at individual sensors. The standard deviation of wind speeds at individual anemometers was larger than the standard deviation of the wind speeds averaged over the eight upwind anemometers. This suggests the importance of rapid temporal wind fluctuations locally, compared to larger-scale flow structures $(>\sim 100 \mathrm{~m})$ that would induce persistent wind speed differences amongst anemometers. Since the S5 plot and areas upwind of it were fairly homogenous on scales of $\sim 100 \mathrm{~m}$, it is to be expected that fewer larger-scale flow structures were present.

The standard deviations for the wind components parallel and perpendicular to the mean wind speed are indicative of the local along-wind and cross-wind gustiness. Values of standard deviation of wind parallel to the mean ranged from $0.76 \mathrm{~ms}^{-1}$ to $0.92 \mathrm{~ms}^{-1}$, or $32 \%$ 
to $39 \%$ of wind speed in this direction (Table 1, C4), consistent with the magnitude of the swings seen in Figure 4a. The standard deviation of the wind components perpendicular to the mean wind direction ranged from $0.38 \mathrm{~ms}^{-1}$ to $0.86 \mathrm{~ms}^{-1}$, or $15 \%$ to $37 \%$ of the mean wind (Table 1, C5). These lateral wind fluctuations were responsible for the differences in local instantaneous wind directions among sensors. As a result, FIRETEC simulations showed strong sensitivity to the timing of ignition or position in space of the sensor used to obtain wind direction (see Section 4).

\subsubsection{Spatial Wind Variability}

The range of mean wind directions across the eight sensors, 60.15 degrees, and the associated variation in $\bar{u}$ and $\bar{v}$ wind components illustrate substantial spatial variability in wind directions relative to a site-wide mean wind. The impact of fluctuations perpendicular to the mean wind decreased as large-scale site-wide mean wind increased. If, for example, the site-wide mean wind had been higher, the same magnitude of fluctuation in the winds would not have resulted in such a wide angular range for the individual anemometer since the angular deviation from the site-mean is proportional to $\sin ^{-1}$ (cross stream perturbation/mean wind speed).

The mean and standard deviation for the $u$ and $v$ velocity components (Table 1 ) reflect the fact that anemometers on the western portion of the upwind anemometer array (A81, A26, A80, A31, and A60) recorded mean flow that is predominantly from the north to northeast (mean $u$ components have much smaller magnitudes than the $v$ components). Wind directions measured at sensors farther to the east (A41, and A42) had a more significant westerly component during this time period (more negative wind angles; green, turquoise lines in Figure $4 b$ ). This behavior - summarized in windrose plots in Figure 5-is indicative of a larger-scale $(>\sim 100 \mathrm{~m})$ structure in the flow that passed through the anemometer array at the time of the burn, giving a macroscale directional trend. This directional trend was different from smaller-scale wind fluctuations at individual anemometers.

\section{Modeling Methods}

\subsection{FIRETEC Domain Setup}

We performed a set of ten FIRETEC simulations, including five simulations driven by data from single anemometers located most directly upwind of the ignition line, A80, A31, A60, A73, A41, and five simulations with winds based on data from multiple sensors. Nine of the ten simulations used heterogeneous fuels as described in Section 2.1. The tenth simulation used a spatially uniform representation of average fuels.

To avoid interactions between the boundaries of the computational domain and fireinduced winds, we used a computational domain significantly larger than the S5 burn plot. Our computational domain was $600 \mathrm{~m}$ by $400 \mathrm{~m}$, and we placed the S5 burn plot (black line in Figure 4) $150 \mathrm{~m}$ from the domain boundary in x direction (direction of the short dimension of the S5 plot) and $200 \mathrm{~m}$ from the domain boundary in y direction (direction of the long dimension of the S5 plot). See Figure 1a,c for a comparison of the domain size with the S5 burn plot. This put the ring of anemometers around the burn plot at least $130 \mathrm{~m}$ from the boundaries. The horizontal grid spacing was $2 \mathrm{~m}$. The computational domain had a vertical extent of $615 \mathrm{~m}$ and the atmospheric stability in the simulations was neutral. We use a stretched vertical coordinate, with an average vertical spacing of $15 \mathrm{~m}$, translating to an actual resolution of $1.5 \mathrm{~m}$ near the ground and $\sim 40 \mathrm{~m}$ near the top of the domain. FIRETEC's compressible atmospheric solver utilizes the method of averages $[42,43]$ to efficiently simulate flows on multiple time scales by splitting highfrequency phenomena from the governing equations by applying two nested time-stepping schemes. The small time-stepping loop, with a time step of $0.002 \mathrm{~s}$, solves for fast-moving waves, which are averaged and fed into the large time step, at $0.02 \mathrm{~s}$, which solves the Navier-Stokes equations. These time steps were chosen to minimize computational expense while resolving required time scales for stability associated with Courant-Friedrichs-Lewy (CFL) criteria for compressible solvers, convective heat transfer and aerodynamic drag. 
Each simulation was run for $500 \mathrm{~s}$. Ignition started after $180 \mathrm{~s}$, and fires burned for $320 \mathrm{~s}$ of simulation time. The time of $320 \mathrm{~s}$ was chosen based on the approximate time that it took the S5 fire to reach the tower in the middle of the plot, as it was a visual marker that could be used for comparison. This 320-s time was also convenient as a balance, allowing fires to burn for long enough time to capture the influences of multiple fluctuations in the wind field but short enough that only one of the simulations burned past the edge of the burn block.

\subsection{Wind Initial and Boundary Conditions}

To simulate a fire exposed to the same conditions as the RxCADRE S5 burn, we used measured anemometer data to prescribe the initial winds throughout the computational domain and evolving upstream winds over the course of the burn. We compared several basic techniques for prescribing these initial and boundary conditions, including: (a) using measurements from individual upstream anemometers, (b) simple averaging of the 8 upstream anemometer measurements (blue circles and labels in Figure 1), (c) averaging only a subset of 4 and 5 upstream anemometers (purple and green flags in Figure 1 respectively), and (d) blending data from the 8 upstream anemometers using a nearest neighbor weighting algorithm. All of these methodologies require spatial extrapolation of the anemometer data to prescribe the dynamic winds at the boundaries of the computational domain and at all points within the domain at the start of the simulation, including winds aloft. Challenges of this process include:

- Adequately representing the spatial and temporal variability of the winds, including the dynamic wind events that influence fire behavior within the S5 plot.

- Using the $3.3 \mathrm{~m}$ high anemometer data to estimate winds aloft.

For simulations based on single anemometers and with 4-, 5- and 8-anemometer average winds, the boundary and initial conditions were based on a single vertical profile (described below). While these methods resulted in horizontally uniform wind field inputs into FIRETEC, the nearest neighbor weighting technique (8NN) generated horizontally heterogeneous values using a distance-weighted average between velocity components measured at the eight sensors. The distance-weighted average was calculated as follows:

$$
\begin{aligned}
& U_{8 n n w}(x, y)=\frac{\sum_{n=1,8} u_{n} * \sqrt{\left(x-x_{\text {sensor }, n}\right)^{2}+\left(y-y_{\text {sensor }, n}\right)^{2}}}{\sum_{n=1,8} \sqrt{\left(x-x_{\text {sensor }, n)^{2}+\left(y-y_{\text {sensor }, n)^{2}}\right.}\right.}} \\
& V_{8 n n w}(x, y)=\frac{\sum_{n=1,8} v_{n} * \sqrt{\left(x-x_{\text {sensor }, n}\right)^{2}+\left(y-y_{\text {sensor }, n}\right)^{2}}}{\sum_{n=1,8} \sqrt{\left(x-x_{\text {sensor }, n)^{2}+\left(y-y_{\text {sensor }, n)^{2}}\right.}\right.}}
\end{aligned}
$$

where $x$ and $y$ are the location of FIRETEC grid cells and $x_{\text {sensor, } n}$ and $y_{\text {sensor, } n}$ specify the location of sensor $n$. The values $x_{\text {sensor, } n}$ and $y_{\text {sensor, } n}$ were used to specify an initial condition, which was immediately made mass consistent by solving the conservation of mass and momentum equations. At the boundaries, winds were relaxed towards these values but conservation of mass and momentum equations assured consistency. In order to allow comparison between time-averaged, ambient winds for the $8 \mathrm{NN}$ simulations and the other simulations in Table 2, mean winds for the $8 \mathrm{NN}$ simulation were computed by averaging the velocity components at 15 evenly spaced points along the ignition line (computed with the nearest neighbor algorithm shown above) for the $320 \mathrm{~s}$ after ignition.

To specify the velocities over the remaining vertical extent of the domain, we vertically blended the rapidly varying surface winds with steady winds aloft, obtained using Equation (5):

$$
\begin{aligned}
& u_{\text {aloft }}(z)=\frac{u_{\text {avg }}}{0.4}\left[\ln \frac{z}{0.1}\right] \\
& v_{\text {aloft }}(z)=\frac{v_{\text {avg }}}{0.4}\left[\ln \frac{z}{0.1}\right]
\end{aligned}
$$

$u_{a v g}$ and $v_{a v g}$ are $10 \mathrm{~min}$ average $u$ and $v$ wind components (from 3 min prior to ignition until $7 \mathrm{~min}$ after ignition) computed by averaging all eight upwind sensors over this time period. The two profiles were blended using an exponential decay weighting such 
that near the ground the velocities matched measured values and aloft the values matched the mean value. The reason for doing this is that the dominant length scales of atmospheric motion are expected to be finer near the ground than higher above the surface. Thus, high frequency perturbations become less significant compared to the mean wind with height. It would be unrealistic to impose the same fluctuations uniformly over the entire vertical extent of the domain or to simply extrapolate these fluctuating winds vertically with a log profile. Additionally, details of the perturbations higher above the ground are not known, and this approach provides a smooth transition between the measured dynamic and heterogeneous velocity field near the ground and winds aloft.

Table 2. Input parameters for the 10 FIRETEC simulations of the S5 burn.

\begin{tabular}{|c|c|c|c|c|c|c|}
\hline Simulation & Surface Wind & Fuels & $\overline{\mathbf{S}}$ & $\bar{\alpha}$ & $\begin{array}{c}\overline{\mathbf{S}} \perp \\
\text { Ig. Line }\end{array}$ & $\begin{array}{c}\bar{S} \| \\
\text { Ig. Line }\end{array}$ \\
\hline A80 & A80 & Heterogeneous & 2.28 & -15.55 & 2.20 & 0.61 \\
\hline A31 & A31 & Heterogeneous & 2.49 & -5.79 & 2.48 & 0.25 \\
\hline A60 & A60 & Heterogeneous & 2.47 & -1.26 & 2.47 & 0.05 \\
\hline A73 & A73 & Heterogeneous & 2.29 & -29.66 & 1.99 & 1.13 \\
\hline A41 & A41 & Heterogeneous & 2.43 & -56.24 & 1.35 & 2.02 \\
\hline 4S_avg & 4-sensor average & Heterogeneous & 2.34 & -12.61 & 2.28 & 0.51 \\
\hline 5S_avg & 5-sensor average & Heterogeneous & 2.33 & -4.56 & 2.32 & 0.19 \\
\hline 8S_avg & 8-sensor average & Heterogeneous & 2.19 & -20.34 & 2.05 & 0.76 \\
\hline $8 \mathrm{NN}-\mathrm{H}$ & Nearest neighbor & Heterogeneous & 2.20 & -22.68 & 2.03 & 0.85 \\
\hline 8NN-U & Nearest neighbor & Uniform (averaged) & 2.20 & -22.68 & 2.03 & 0.85 \\
\hline
\end{tabular}

Overall, the mean wind speeds of the composite simulations were slower than those of the single anemometers (Table 2) because the composite wind calculation sumed instantaneous observations with different (and sometimes counteracting) mean directions. The measured mean wind directions for the five upwind anemometers (Table 2) ranged over nearly 55 degrees ( -1.26 degrees to -56.24 degrees clockwise from north) during the $320 \mathrm{~s}$ of simulation after ignition, with a significant westerly component. The winds in the composite simulations had a much smaller range of nearly 14 degrees ( -12.61 to -26.5 degrees), which was relatively northerly compared to the range of the individual anemometers.

\subsection{Ignition}

In the RxCADRE experiment, the ignition line was established by two individuals moving with drip torches in opposite directions from the center of the ignition to the two ends of the line. Documented locations of these points are marked by three orange circles in Figure 3. The speed at which the igniters traveled was reported to be $1.34 \mathrm{~m} \mathrm{~s}^{-1}$ in field experiment documents. The result of this procedure, which we emulated when setting up the ignition in FIRETEC simulations, is an ignition line that grows from its center towards the ends.

\section{Modeling Results and Discussion Fire Spread}

We computed the downwind spread rate of the 10 simulated fires based on the farthest downwind distance traveled in the direction of the simulation-specific mean wind. The spread distance was calculated as the distance between each grid cell along the fire perimeter at $320 \mathrm{~s}$ and the ignition line along the mean wind direction. Because the mean wind direction is different for each simulation, the distance traveled was computed in a different direction for each simulation. This rate of spread in the direction of the simulationspecific mean wind ( $\operatorname{ROS}_{\mathrm{SSWind}}$ ) in $\mathrm{m} \mathrm{s}^{-1}$ is the maximum downwind spread distance, divided by $320 \mathrm{~s}$. For comparison, we have also computed spread rates using the average wind direction from all eight upwind sensors, ROS $_{8 \mathrm{avg}}$. We estimated area burned and the fire perimeter based on consumption of fine fuel. For the purpose of this study, a fuel consumption of $25 \%$ was used to change the designation of a particular computational 
cell from unburned to burned. Area burned was calculated at $320 \mathrm{~s}$ after ignition for all simulations (Table 3).

Table 3. Overview of simulation results, including fire spread metrics rate of spread and area burned for the 10 simulations.

\begin{tabular}{cccc}
\hline Simulation & ROS $_{\text {SSWind }}\left(\mathbf{m ~ s}^{-1}\right)$ & $\begin{array}{c}\text { ROS }_{\mathbf{8} \text { avg }} \\
\left(\mathbf{m ~ s}^{-\mathbf{1}}\right)\end{array}$ & $\begin{array}{c}\text { Area Burned 320 s } \\
\text { after Ignition } \mathbf{( m}^{\mathbf{2}} \text { ) }\end{array}$ \\
\hline A80 & 0.279 & 0.278 & 2676 \\
A31 & 0.359 & 0.347 & 4108 \\
A60 & 0.504 & 0.476 & 5424 \\
A73 & 0.324 & 0.320 & 3592 \\
A41 & 0.118 & 0.096 & 1212 \\
4S_avg & 0.380 & 0.377 & 4260 \\
5S_avg & 0.392 & 0.378 & 4404 \\
8S_avg & 0.322 & 0.322 & 3452 \\
8NN-H & 0.413 & 0.413 & 3444 \\
8NN-U & 0.531 & 0.531 & 5540 \\
\hline
\end{tabular}

Of all simulations, A60 and 8NN-U resulted in the largest area burned. These two simulations represent the uniform fuel case $(8 \mathrm{NN}-\mathrm{U})$, which used nearest neighbor winds, and the simulation with the winds most consistently perpendicular to the ignition line (A60). These simulations also produced the highest ROS. Overall, we found a linear relationship between ROS and area burned, as is to be expected for wind driven fires, since the wind driven heading rate of spread is significantly larger than the flanking spread rates. Differences between the two ROS metrics were small, and the relationship with area burned held for both.

Figure 6 shows fuel load at 320 s after ignition for the five simulations forced with single sensor wind data. Areas of low fuel load (blue) indicate fuel consumed by the fires, and correspond to fire perimeters. Only the area of the S5 burn plot is shown, rather than the entire computational domain. Note that these images have been rotated compared to the plot layout shown in Figure 3. For reference, north is marked with a black arrow and mean wind direction and magnitude are marked with a purple vector. An approximate outline of the actual S5 fire perimeter from infrared imagery is added in black. Infrared imagery shows heated areas, which are related to the fire perimeter, but are not precisely the same and thus this outline is provided only as a reference. Figure 6 illustrates significant qualitative variation between the five burn perimeters, or areas of significant fuel consumption. Since everything else was identical between the simulations, this variation in fuel consumption or fire extent can be tied directly to variation in the wind speed and direction recorded at the different anemometers. The largest deviation in the extent of fire spread from the approximate S5 perimeter was observed for A41. This anemometer recorded a wind direction with a significant along-ignition-line component. The resulting area burned was much smaller than in other simulations where the observed winds had a higher magnitude perpendicular to the ignition line. For orientation, the A41 sensor was located towards the bottom left side of the burn plot as oriented in Figure 6. A73 was to the left of the lower left corner and A60, A31 and A80 were located along the bottom of the burn plot from left to right.

The burn perimeters for the 4S_avg, 5S_avg, 8S_avg, 8NN-H simulations at $320 \mathrm{~s}$ after ignition are shown in Figure 7. Differences in fuel consumption, showing the extent of fire spread, continued to persist when using different composite winds, though they were less pronounced than for individual anemometers. Ranges of wind speeds and wind directions were smaller for composite winds. 

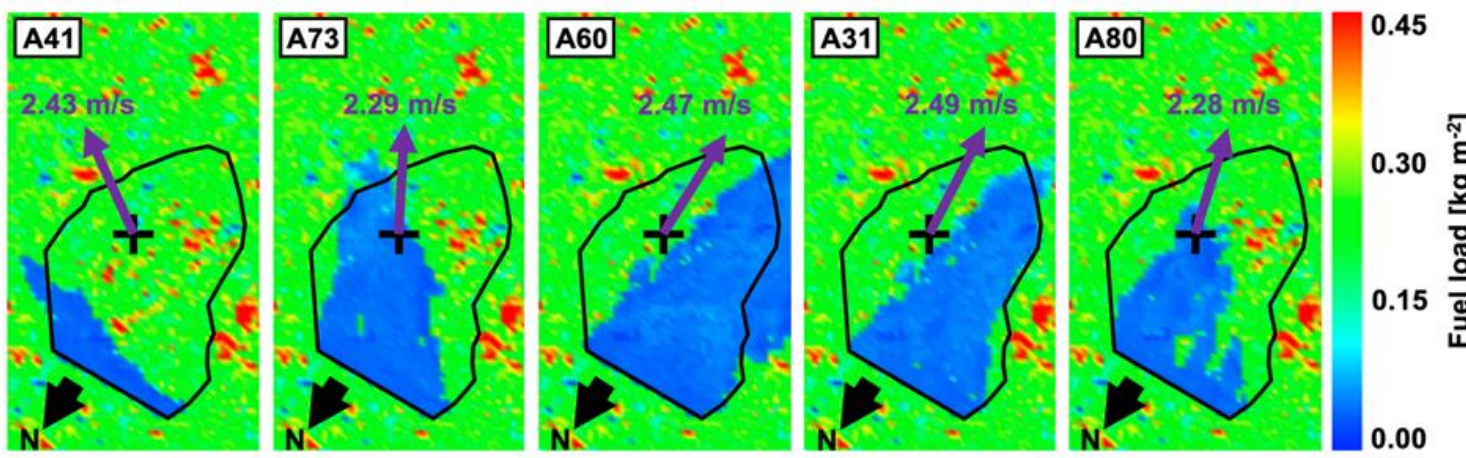

Figure 6. FIRETEC simulations of fuel consumption within the S5 burn plot $320 \mathrm{~s}$ after ignition. A black arrow in lower left of each panel denotes direction of magnetic north. All simulations are initialized with wind data from individual anemometers (from left to right) A41, A73, A60, A31, and A60. The purple arrows denote mean direction and associated magnitude of the wind for each simulation. The black outline is the approximate fire perimeter in the Prescribed Fire Combustion and Atmospheric Dynamics Research Experiments (RxCADRE) experiment, based on infrared imagery. In the case of the A60 simulation, the fire burned past the extent of the burn block and continues burning. Fuel consumption is shown on the S5 burn plot domain, not the entire.
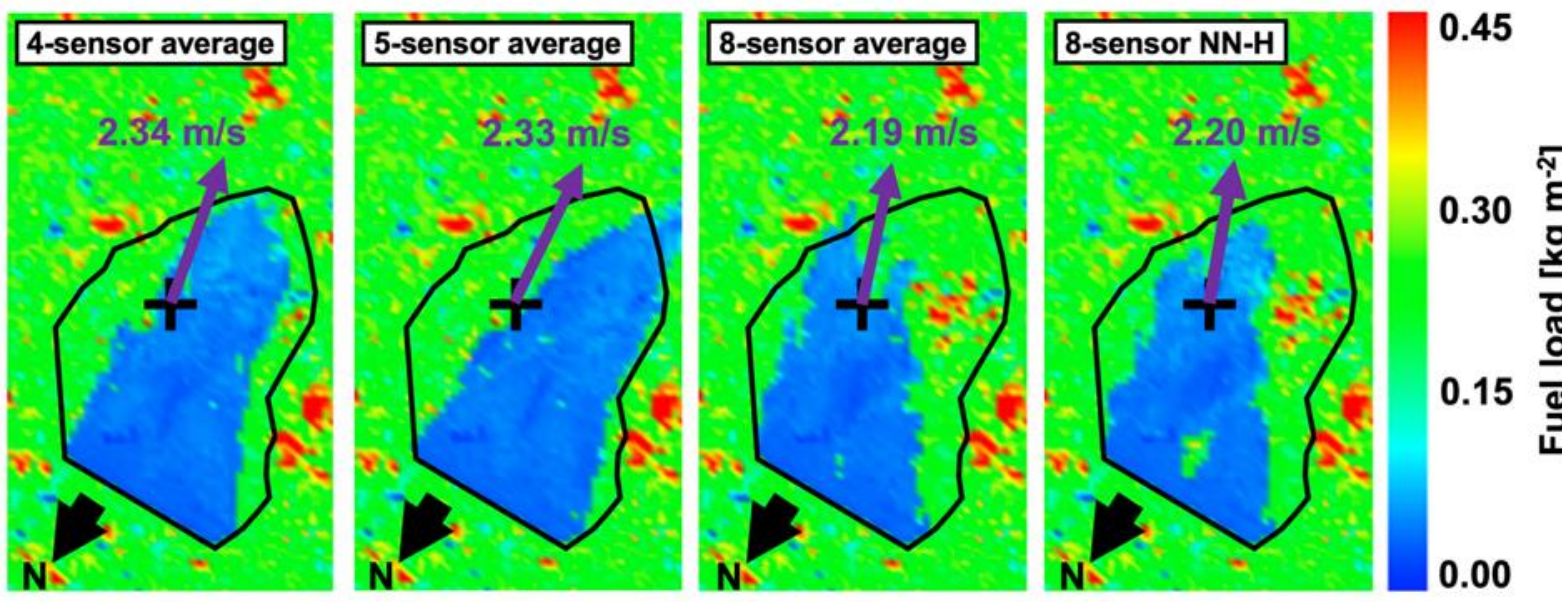

Figure 7. FIRETEC simulations, initialized with averaged wind data, of fuel consumption within the S5 burn plot $320 \mathrm{~s}$ after ignition. Four-sensor average winds are generated by averaging data from anemometers A31, A60, A73, and A80. Five-sensor average winds are generated using anemometers A26, A31, A60, A80, and A81. Eight-sensor average and eight-sensor nearest neighbor winds are generated using anemometers A26, A31, A41, A42, A60, A73, A80, and A81. Fuel consumption is shown on the S5 burn plot domain, not the entire computational grid.

The ROS values for the five single-anemometer simulations in the direction of the mean wind for each specific simulation ranged from $0.118 \mathrm{~m} \mathrm{~s}^{-1}$ to $0.504 \mathrm{~m} \mathrm{~s}^{-1}$. Spread rates for each simulation are plotted as circles in Figure 8a. Each circle is colored by the average wind speed used to drive the simulation. Open circles represent ROS in the direction of simulation-specific wind, while filled circles represent ROS in the direction of sensor-average wind. In order to calculate this value, we projected the simulation-specific wind on the eight-sensor average direction of -20.34 degrees. Significant differences between these two ROS estimates were found for the three single-anemometer simulations associated with A31, A41 and A60, which recorded the largest differences between their individual mean wind directions and the direction of the eight-sensor average. A31 and A60 had the strongest mean wind components perpendicular to the ignition line (the intended downwind direction when the experiment was designed). A41 had the weakest wind speed component perpendicular to the ignition line, and strongest wind component parallel to the ignition line (the intended crosswind direction). Even though the simulation average wind speed was higher than the eight-sensor average, it had the slowest spread 
rate and smallest area burned as the projection of the ignition line length in the direction of the wind was smallest. The wind composite simulations were more closely aligned with the eight-sensor average wind (5S-avg was most divergent with a $<16$ degree difference in mean wind direction) and their projected rates of spread were close to rates of spread in the direction of simulation-specific wind. Figure 8 also shows less overall variability in ROS among the composite simulations than among the single anemometer simulations. This is related to the fact that there is less variation in mean wind speed, $2.19 \mathrm{~m} \mathrm{~s}^{-1}$ to $2.34 \mathrm{~m} \mathrm{~s}^{-1}(\sim 7 \%)$, as well as the narrower range of mean wind directions that only spans about 16 degrees. This narrower range means that the projection of the ignition line perpendicular to wind speed is much more consistent than among the single anemometer simulations.

(a) Single anemometer winds

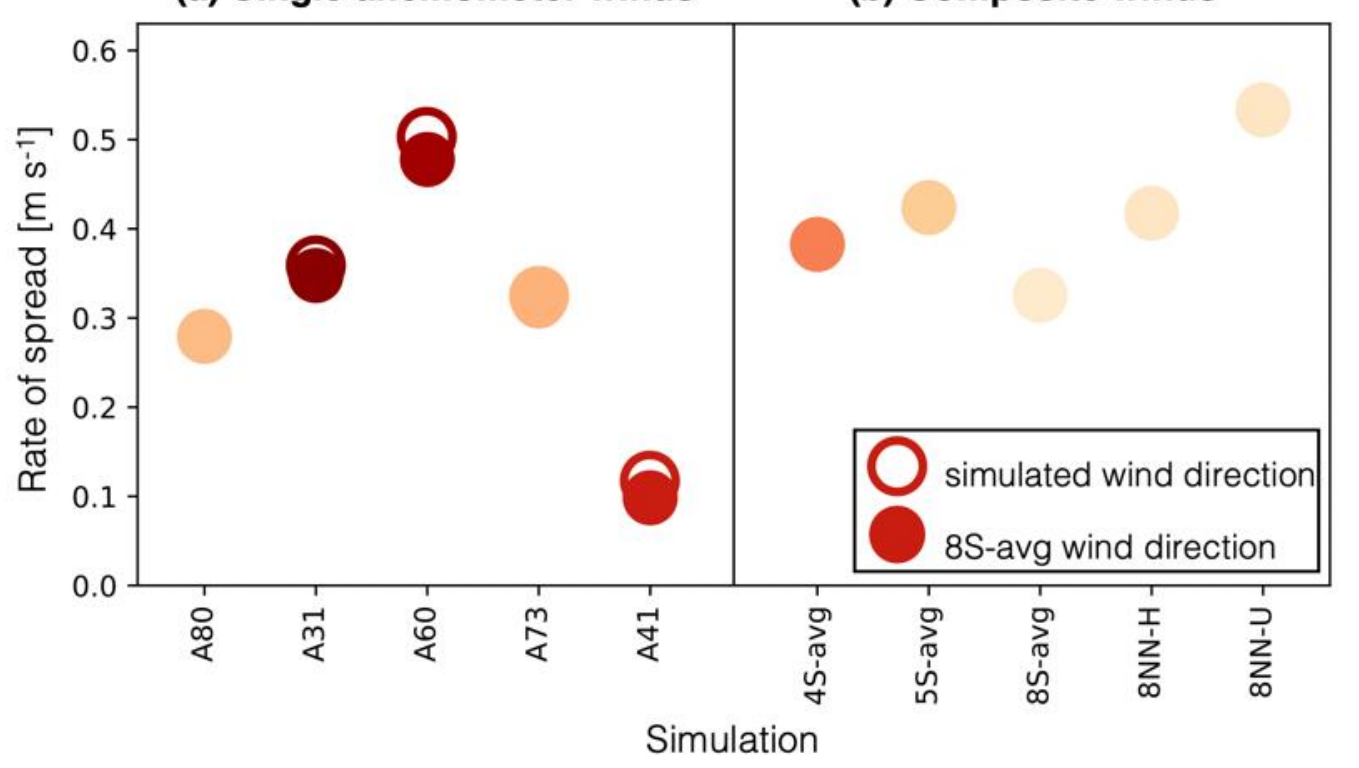

\section{(b) Composite winds}

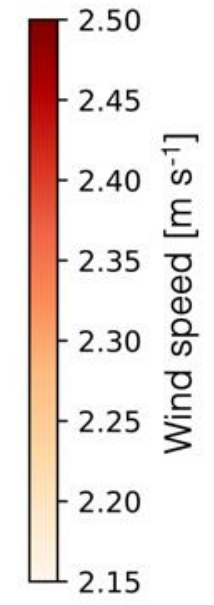

Figure 8. Spread rates for single anemometer (a) and composite wind (b) simulations plotted as a function of simulation specific (open circles) and eight-sensor average (filled circles) wind speed.

Single-anemometer simulations were arranged in Figure 8 to correspond to the locations of the sensors from west to east. For the three sensors directly upwind of the simulation domain (A80, A31, A60), ROS increased from west to east. ROS then decreased sharply moving farther east to sensors A73 and A41. Because the range in ROS was affected by both wind speed and orientation of the ignition line with respect to the wind direction, ROS was not correlated with wind speed for either the single-anemometer simulations or the composite simulations. Past observations and numerical explorations [44-47] have noted that the length of the fire line impacts spread rate (increased ROS for longer fire lines) when the line is perpendicular to the mean wind. Thus, for a shorter projection of the line perpendicular to the wind, we would expect the spread rate to be less influenced by the mean wind, which was indeed observed for A41.

The simulation with homogeneous fuels, $8 \mathrm{NN}-\mathrm{U}$, used the same wind conditions as $8 \mathrm{NN}-\mathrm{H}$. Thus, differences between the two simulations can be attributed to the arrangement of fuels. We see a significantly larger rate of spread ( $29 \%$ increase) and area burned $(60 \%$ increase) for $8 \mathrm{NN}-\mathrm{U}$ than for $8 \mathrm{NN}-\mathrm{H}$. This suggests that for variable fuels, locations where fuels, or lack thereof, dampen fire spread have a larger impact than those where fuels accelerate fire spread. This nonlinear influence of fuels on fire spread is confirmed by other studies [48].

In general, fire metrics for the composite wind simulations had narrower ranges than did fire metrics computed from single anemometer simulations. This is expected given the greater similarity in wind speeds and directions. Fires in the composite wind simulations 
exhibited more similarities with the observed fire (Figure 9) in terms of spread patterns. This improved agreement suggests that developing wind fields from combinations of measurements will likely provide some benefits over the use of a single anemometer. The effects of localized variations that are observed at individual anemometers are moderated by combining them with variations from other locations. The variation in wind direction illustrates that caution should be used in associating any single measurement with the spread of the fire.

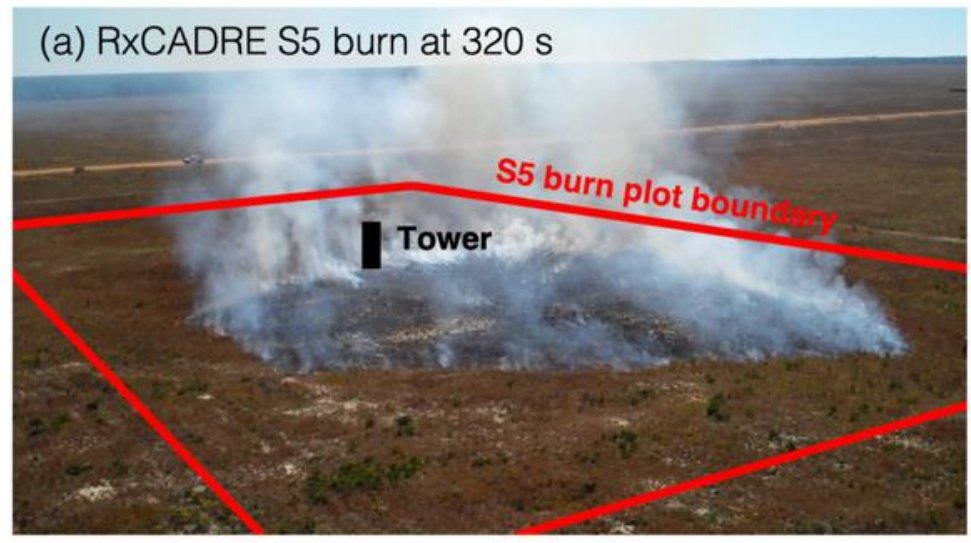

(b) Simulation with 8-sensor NN-H winds at $320 \mathrm{~s}$

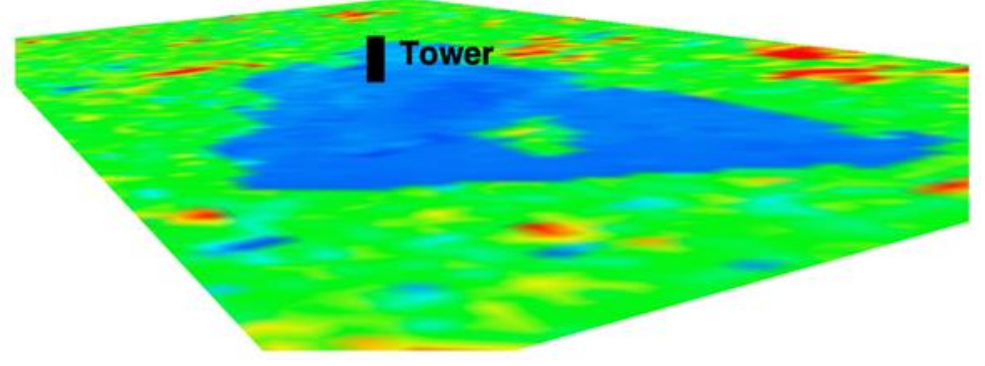

Figure 9. S5 burn from RxCADRE (a) and FIRETEC nearest neighbor simulation (b), both at $320 \mathrm{~s}$ after ignition. The red lines in the RxCADRE image show the extent of the FIRETEC computational grid. The black marker in the center of each image marks the location of an instrument tower. The large blue area in the FIRETEC image indicates the modeled burn area. A comparison between these images highlights obvious differences in fire progression.

Figure 9 shows differences in fire shape between the S5 burn and eight-sensor nearest neighbor algorithm simulation at $320 \mathrm{~s}$. The most striking difference can be seen along the left flank of the fire. While in the observed S5 fire the area burned extended along an almost straight flank, we observed a jagged line, with significantly less consumption, in the simulation. A41 was the closest anemometer to this region. Interestingly, although the simulation using A41 data showed a significantly different overall spread pattern, it did feature increased fire behavior in this region. This suggests that the details of the winds measured by A41 might have had a localized effect on fire spread.

\section{Conclusions}

Here we have described simulations of a field experiment involving a fire burning under marginal conditions using the physics-based coupled fire/atmosphere model FIRETEC. While a comparison with other coupled fire-atmosphere models would be a valuable contribution, it is beyond the scope of the current study. Approaches for developing heterogeneous fuels inputs and dynamic wind conditions to initialize and bound FIRETEC simulations to reflect the fire environment of the RxCADRE S5 burn were described. Some of the ambiguities involved in translating field data to simulation inputs, as well as sensitivities of simulation results to uncertainty in the field data used, were 
illustrated. Although this particular burn was considered one of the most consistent of the small RxCADRE burns conducted in 2012 in terms of winds, fire activity, and fuels, the fire environment still exhibited variable winds and heterogeneous fuel at the scales of meters to tens of meters. Through the efforts to simulate this experimental fire, we have gained a significant appreciation for some of the challenges of sufficiently characterizing the dynamic and heterogeneous burn environment when directly comparing simulated quantities with observations.

The RxCADRE S5 burn was instrumented with 28 anemometers which collected measurements of wind speed and direction. Ten of these anemometers were upwind of the fire and were likely not influenced by the presence of the fire. Wind direction measurements from two of the ten upwind anemometers were considered outliers and excluded from this study. Measurements from the other eight upwind anemometers were more consistent. While it is plausible that these anemometers had calibration errors as well, it was not possible to distinguish between natural variability and errors for these sensors. Spatial trends between the eight upwind sensors suggest that at least some of their variability was associated with heterogeneity within the wind field.

In setting boundary conditions for a physics-based model, it is important to not use winds that are influenced by the entrainment of the fire itself, since this would essentially result in fire-perturbed wind perturbing a fire (double-counting the coupling between the fire and atmosphere). We have examined several methods for using upstream anemometers to set upwind boundary conditions for models like FIRETEC, including the use of single anemometers and a composite of the winds measured at multiple locations. We observed a large range of simulated fire behaviors resulting from using wind speeds measured at five different locations, all within $120 \mathrm{~m}$ of the fire line, and within $\sim 150 \mathrm{~m}$ of each other. While two of the simulations showed similarities to observed fire spread patterns, the clear challenge is to know which anemometer to use a priori. Based on the large range of fire outcomes, we conclude that when the spatial and temporal variability of the wind speed and direction is significant compared to the mean wind speed, using a single anemometer to specify the upwind wind conditions is simply unreliable. The local (space and time) fluctuations at one specific site are often not consistent with those of the macroscale wind field or other upwind locations, even in a large open grassland with negligible topographic relief sampled in RxCADRE. As a result, fire simulations based on single anemometers reflect wholly local wind conditions.

The simulations with wind data derived from a combination of upwind anemometers showed more consistency in terms of fire spread rates and patterns. However, the details of fire spread depended on which anemometers were included in the composite and how they are integrated. We explored the use of both simple averaging and a nearest neighbor algorithm, which produced different results. Since fire activity depends on the interaction between fire and atmosphere at local scales, damping out the heterogeneities through averaging is likely to produce differences between simulated and observed fire behavior.

A key takeaway from this effort to compare physics-based model results to observations in marginal conditions is that characterizing variation in the winds and fuels at multiple scales is critical for model evaluation. These types of models force the user to explicitly define the plane of upwind winds throughout the simulation and the spatial arrangement of fuels, so the need to address this variability is self-evident. In simpler models, accounting for these details might not be necessary, or even possible. However, simpler models make assumptions about the wind and fuel conditions (such as homogeneity) that could limit their ability to accurately represent marginal fire. It is important to (1) understand what the fundamental assumptions of the model are, and what the sensitivity of the modeled behavior is to violations of those assumptions (if assuming constant winds, how much error might this cause compared to real variable winds), and (2) understand the potential uncertainty in the inputs and what the sensitivity of the modeled behavior is to this uncertainty. 
The lessons learned from this paper have important implications for future wildland fire observation campaigns of both low and high intensity fires; even intense fires often exhibit marginal flanking or backing behavior for portions of the fire. If observations are to be used for model development or model evaluation [49] it is important to understand whether the environmental conditions have been adequately characterized to directly stipulate model input conditions. One way to achieve this understanding is to perform simulations with this type of model before the experiment using hypothetical measurement to constrain model inputs and identify any assumptions that must be made to complete the initialization of the model. By exploring the sensitivity of model results to the assumptions required to complete the inputs, it is possible to understand what additional measurements are important for appropriate comparison against models.

While this manuscript is primarily focused on describing the process and lessons learned from FIRETEC simulations of one of the simplest of the RxCADRE fires, synergistic work explores a more thorough characterization of the sensitivity of marginal fire spread modeled using FIRETEC to variability in wind and fuels $[3,48]$.

Author Contributions: Conceptualization: R.R.L., J.K.H., J.H.F., B.W., J.L.W., and J.J.O.; methodology: R.R.L., J.K.H., J.H.F., B.W., J.L.W., and S.G.; software: R.R.L., J.L.W., and A.J.; formal analysis: R.R.L., J.L.W., A.J, and K.M.Y.; resources: R.R.L., J.H.F., B.W., and J.J.O.; writing-original draft preparation: R.R.L., A.J., K.M.Y., J.H.F., B.W., J.K.H., and J.J.O.; writing-review and editing: A.J., R.R.L., and K.M.Y.; visualization: A.J. and J.L.W.; project administration: J.H.F., S.G., and R.R.L.; funding acquisition: J.H.F. and S.G. All authors have read and agreed to the published version of the manuscript.

Funding: This research was funded by the Department of Defense Environmental Security and Technology Certification Program (ESTCP), grant number 13 E-RC3-010 and Strategic Environmental Research and Development Program (SERDP) grant number RC-2643.

Institutional Review Board Statement: Not applicable.

Informed Consent Statement: Not applicable.

Data Availability Statement: The data presented in this study are available on request from the corresponding author. The data are not publicly available due to large data volume.

Acknowledgments: In addition to the funding provided by ESTCP and SERDP programs, the Air Force Wildland Fire Branch, USDA Forest Service and Eglin Air Force Base contributed expertise and resources that made this work possible. Computational resources for this work were provided by Los Alamos National Laboratory Institutional Computing Program.

Conflicts of Interest: The authors declare no conflict of interest.

\section{References}

1. Hoffman, C.; Sieg, C.; Linn, R.; Mell, W.; Parsons, R.; Ziegler, J.; Hiers, J. Advancing the Science of Wildland Fire Dynamics Using Process-Based Models. Fire 2018, 1, 32. [CrossRef]

2. Hiers, J.K.; O’Brien, J.J.; Varner, J.M.; Butler, B.W.; Dickinson, M.; Furman, J.; Gallagher, M.; Godwin, D.; Goodrick, S.L.; Hood, S.M.; et al. Prescribed fire science: The case for a refined research agenda. Fire Ecol. 2020, 16, 1-15. [CrossRef]

3. Jonko, A.; Yedinak, K.; Linn, R.; Parsons, R.; Atchley, A.; Conley, J. Sensitivity of grassfires to small perturbations in the turbulent wind field. J. Geophys. Res. Atmos. In review.

4. Ottmar, R.D.; Hiers, J.K.; Butler, B.W.; Clements, C.B.; Dickinson, M.B.; Hudak, A.T.; O’Brien, J.J.; Potter, B.E.; Rowell, E.M.; Strand, T.M.; et al. Measurements, datasets and preliminary results from the RxCADRE project-2008, 2011 and 2012. Int. J. Wildl. Fire 2016, 25, 114. [CrossRef]

5. Sullivan, A.L. Wildland surface fire spread modelling, 1990-2007. 1: Physical and quasi-physical models. Int. J. Wildl. Fire 2009, 18, 349-368. [CrossRef]

6. Sullivan, A.L. Wildland surface fire spread modelling, 1990-2007. 2: Empirical and quasi-empirical models. Int. J. Wildl. Fire 2009, 18, 369-386. [CrossRef]

7. Rothermel, R.C. A Mathematical Model for Predicting Fire Spread in Wildland Fuels. 1972. Available online: https://www.fs.fed. us/rm/pubs_int/int_rp115.pdf (accessed on 15 January 2020).

8. Burgan, R.E.; Rothermel, R.C. BEHAVE: Fire Behavior Prediction and Fuel Modeling System-FUEL Subsystem. 1984. Available online: https: / /www.fs.usda.gov/treesearch/pubs/29616 (accessed on 15 January 2020). 
9. Hiers, J.K.; Stauhammer, C.L.; O’Brien, J.J.; Gholz, H.L.; Martin, T.A.; Hom, J.; Starr, G. Fine dead fuel moisture shows complex lagged responses to environmental conditions in a saw palmetto (Serenoa repens) flatwoods. Agric. For. Meteorol. 2019, 266-267, 20-28. [CrossRef]

10. Chiodi, A.M.; Larkin, N.S.; Varner, J.M. An analysis of Southeastern US prescribed burn weather windows: Seasonal variability and El Niño associations. Int. J. Wildl. Fire 2018, 27, 176-189. [CrossRef]

11. Wade, D.D.; Lunsford, J.D.; Dixon, M.J.; Mobley, H.E. A Guide for Prescribed Fire in Southern Forests; US Department of Agriculture: Washington, DC, USA, 1989.

12. Zhou, X.; Mahalingam, S.; Weise, D. Modeling of marginal burning state of fire spread in live chaparral shrub fuel bed. Combust. Flame. 2005, 143, 183-198. [CrossRef]

13. Hoffman, C.M.; Linn, R.; Parsons, R.; Sieg, C.; Winterkamp, J. Modeling spatial and temporal dynamics of wind flow and potential fire behavior following a mountain pine beetle outbreak in a lodgepole pine forest. Agric. For. Meteorol. 2015, 204, 79-93. [CrossRef]

14. Overholt, K.J.; Kurzawski, A.J.; Cabrera, J.; Koopersmith, M.; Ezekoye, O.A. Fire behavior and heat fluxes for lab-scale burning of little bluestem grass. Fire Saf. J. 2014, 67, 70-81. [CrossRef]

15. Overholt, K.J.; Cabrera, J.; Kurzawski, A.; Koopersmith, M.; Ezekoye, O.A. Characterization of Fuel Properties and Fire Spread Rates for Little Bluestem Grass. Fire Technol. 2014, 50, 9-38. [CrossRef]

16. Mueller, E.; Mell, W.; Simeoni, A. Large eddy simulation of forest canopy flow for wildland fire modeling. Can. J. For. Res. 2014, 44, 1534-1544. [CrossRef]

17. Dupuy, J.-L.; Pimont, F.; Linn, R.R.; Clements, C.B. FIRETEC evaluation against the FireFlux experiement: Preliminary results. In Advances in Forest Fire Research. Proceedings of the 7th ICFFR; Viegas, D.X., Ed.; Coimbra University Press: Coimbra, Portugal, 2014.

18. Kochanski, A.K.; Jenkins, M.A.; Mandel, J.; Beezley, J.D.; Clements, C.B.; Krueger, S. Evaluation of WRF-SFIRE performance with field observations from the FireFlux experiment. Geosci. Model Dev. 2013, 6, 1109-1126. [CrossRef]

19. Linn, R.R.; Cunningham, P. Numerical simulations of grass fires using a coupled atmosphere-fire model: Basic fire behavior and dependence on wind speed. J. Geophys. Res. Atmos. 2005, 110, 1-19. [CrossRef]

20. Linn, R.; Anderson, K.; Winterkamp, J.; Brooks, A.; Wotton, M.; Dupuy, J.-L.; Pimont, F.; Edminster, C. Incorporating field wind data into FIRETEC simulations of the International Crown Fire Modeling Experiment (ICFME): Preliminary lessons learned. Can. J. For. Res. 2012, 42, 879-898. [CrossRef]

21. Mallia, D.V.; Kochanski, A.K.; Urbanski, S.P.; Lin, J.C. Optimizing Smoke and Plume Rise Modeling Approaches at Local Scales. Atmosphere 2018, 9, 166. [CrossRef]

22. Mallia, D.V.; Kochanski, A.K.; Urbanski, S.P.; Mandel, J.; Farguell, A.; Krueger, S.K. Incorporating a Canopy Parameterization within a Coupled Fire-Atmosphere Model to Improve a Smoke Simulation for a Prescribed Burn. Atmosphere 2020, $11,832$. [CrossRef]

23. Alexander, M.E.; Cruz, M.G. Are the applications of wildland fire behaviour models getting ahead of their evaluation again? Environ. Model. Softw. 2013, 41, 65-71. [CrossRef]

24. Davis, A.Y.; Ottmar, R.; Liu, Y.; Goodrick, S.; Achtemeier, G.; Gullett, B.; Aurell, J.; Stevens, W.; Greenwald, R.; Hu, Y.; et al. Fire emission uncertainties and their effect on smoke dispersion predictions: A case study at Eglin Air Force Base, Florida, USA. Int. J. Wildl. Fire 2015, 24, 276-285. [CrossRef]

25. Achtemeier, G.L.; Goodrick, S.A.; Liu, Y. Modeling multiple-core updraft plume rise for an aerial ignition prescribed burn by coupling daysmoke with a cellular automata fire model. Atmosphere 2012, 3, 352-376. [CrossRef]

26. O'Brien, J.J.; Loudermilk, E.L.; Hornsby, B.; Hudak, A.T.; Bright, B.C.; Dickinson, M.B.; Hiers, J.K.; Teske, C.; Ottmar, R.D. High-resolution infrared thermography for capturing wildland fire behaviour: RxCADRE 2012. Int. J. Wildl. Fire 2016, 25, 62-75. [CrossRef]

27. Hudak, A.T.; Dickinson, M.B.; Bright, B.C.; Kremens, R.L.; Loudermilk, E.L.; O’Brien, J.J.; Hornsby, B.S.; Ottmar, R.D. Measurements relating fire radiative energy density and surface fuel consumption-RxCADRE 2011 and 2012. Int. J. Wildl. Fire 2016, 25, 25-37. [CrossRef]

28. Clements, C.B.; Lareau, N.P.; Seto, D.; Contezac, J.; Davis, B.; Teske, C.; Zajkowski, T.J.; Hudak, A.T.; Bright, B.C.; Dickinson, M.B.; et al. Fire weather conditions and fire-atmosphere interactions observed during low-intensity prescribed fires-RxCADRE 2012. Int. J. Wildl. Fire 2016, 25, 90-101. [CrossRef]

29. Linn, R.R. A Transport Model for Prediction of Wildfire Behavior. Doctoral Thesis, New Mexico State University, Las Cruces, NM, USA, 1997.

30. Linn, R.R.; Harlow, F.H. Computational Technologies for Fluid/Structural/Chemical Systems with Industrial Applications; Kleijn, C.R., Kawano, S., Kudriavtsev, V.V., Eds.; ASME: New York, NY, USA, 1998; pp. 161-168.

31. Linn, R.R.; Reisner, J.; Colman, J.J.; Winterkamp, J.L. Studying wildfire behavior using FIRETEC. Int. J. Wildl. Fire 2002, 11, 233. [CrossRef]

32. Cunningham, P.; Linn, R.R. Numerical simulations of grass fires using a coupled atmosphere-fire model: Dynamics of fire spread. J. Geophys. Res. 2007, 112, D05108. [CrossRef]

33. Dupuy, J.-L.; Linn, R.R.; Konovalov, V.; Pimont, F.; Vega, J.A.; Jiménez, E. Exploring three-dimensional coupled fire-Atmosphere interactions downwind of wind-driven surface fires and their influence on backfires using the HIGRAD-FIRETEC model. Int. J. Wildl. Fire 2011, 20, 734. [CrossRef] 
34. Mell, W.; Jenkins, M.A.; Gould, J.; Cheney, P. A physics-based approach to modelling grassland fires. Int. J. Wildl. Fire 2007, 16, 1. [CrossRef]

35. Accary, G.; Meradji, S.; Morvan, D.; Bessonov, O.; Fougere, D. FireStar3D: 3D finite volume model for the prediction of wildfires. In Proceedings of the VII International Conference of Forest Fire Research, Coimbra, Portugal, 17-20 November 2014.

36. Rowell, E.M.; Seielstad, C.A.; Ottmar, R.D. Development and validation of fuel height models for terrestrial lidar-RxCADRE 2012 Int. J. Wildl. Fire 2016, 25, 38-47. [CrossRef]

37. Hudak, A.T.; Bright, B.C. RxCADRE 2011 and 2012: Predicted Surface Fuel Maps; Forest Service Research Data Archive: Fort Collins, CO, USA, 2018. [CrossRef]

38. Hudak, A.T.; Bright, B.C.; Williams, B.W.; Hiers, J.K. RxCADRE 2011 and 2012: Ignition Data; Forest Service Research Data Archive: Fort Collins, CO, USA, 2018. [CrossRef]

39. Seto, D.; Clements, C.B. RxCADRE 2012: In-Site Wind, Air Temperature, Barometric Pressure, and Heat Flux Time Series Data; Forest Service Research Data Archive: Fort Collins, CO, USA, 2015. [CrossRef]

40. Hiers, J.K.; O’Brien, J.J.; Mitchell, R.J.; Grego, J.M.; Loudermilk, E.L. The wildland fuel cell concept: An approach to characterize fine-scale variation in fuels and fire in frequently burned longleaf pine forests. Int. J. Wildl. Fire 2009, 18, 315. [CrossRef]

41. Rowell, E.; Loudermilk, E.L.; Hawley, C.; Pokswinski, S.; Seielstad, C.; Queen, L.L.; O’Brien, J.J.; Hudak, A.T.; Goodrick, S.; Hiers, J.K. Coupling terrestrial laser scanning with 3D fuel biomass sampling for advancing wildland fuels characterization. For. Ecol. Manag. 2020, 462, 117945. [CrossRef]

42. Reisner, J.; Wynne, S.; Margolin, L.; Linn, R.R. Coupled Atmospheric-Fire Modeling Employing the Method of Averages. Mon. Weather Rev. 2000, 128, 3683-3691. [CrossRef]

43. Nadiga, B.T.; Hecht, M.W.; Margolin, L.G.; Smolarkiewicz, P.K. On simulating flows with multiple time scales using a method of averages. Theor. Comput. Fluid Dyn. 1997, 9, 281-292. [CrossRef]

44. Cheney, N.; Gould, J.; Catchpole, W. The Influence of Fuel, Weather and Fire Shape Variables on Fire-Spread in Grasslands. Int. J. Wildl. Fire 1993, 3, 31. [CrossRef]

45. Linn, R.; Winterkamp, J.; Colman, J.J.; Edminster, C.; Bailey, J.D. Modeling interactions between fire and atmosphere in discrete element fuel beds. Int. J. Wildl. Fire 2005, 14, 37-48. [CrossRef]

46. Pimont, F.; Dupuy, J.-L.; Linn, R.R. Coupled slope and wind effects on fire spread with influences of fire size: A numerical study using FIRETEC. Int. J. Wildl. Fire 2012, 21, 828. [CrossRef]

47. Canfield, J.M.; Linn, R.R.; Sauer, J.A.; Finney, M.; Forthofer, J. A numerical investigation of the interplay between fireline length, geometry, and rate of spread. Agric. For. Meteorol. 2014. [CrossRef]

48. Atchley, A.L.; Linn, R.R.; Jonko, A.; Hoffman, C.M.; Hyman, J.D.; Pimont, F.; Sieg, C.; Middleton, R. Effects of fuel spatial distribution on wildland fire behavior. Int. J. Wildl. Fire 2021, WF20093.

49. Prichard, S.; Larkin, N.; Ottmar, R.; French, N.; Baker, K.; Brown, T.; Clements, C.; Dickinson, M.; Hudak, A.; Kochanski, A.; et al. The Fire and Smoke Model Evaluation Experiment-A Plan for Integrated, Large Fire-Atmosphere Field Campaigns. Atmosphere 2019, 10, 66. [CrossRef] 